\title{
O Emprego e as Empresas do Complexo Portuário do Açu: relato de uma pesquisa
}

\author{
Employment and Companies of the Açu Port Complex: A Research Report
}

Resumo: 0 texto tem como objetivo analisar o perfil das novas empresas que se instalaram no Complexo Industrial e Portuário do Açu, no município de São João da Barra (RJ), suas relações econômicas com a região e seu relacionamento com as administrações públicas locais. A elaboração do texto baseou-se em dados de pesquisa de campo, além de pesquisa bibliográfica e documental, que teve como objetivo o levantamento de dados até então inéditos. Seus resultados indicam que, dada a complexidade das operações por elas desenvolvidas, as relações comerciais com empresas locais são frágeis. Em particular, os gastos com a aquisição de equipamentos e mão de obra especializada não foram nem serão tão cedo realizados localmente, o que limita a capacidade indutora desses investimentos sobre a economia local/regional.

Palavras-chave: Porto do Açu. Emprego.São João da Barra.
Abstract: The purpose of the article is to examine the profile of the new companies that have settled in the Industrial and Port Complex of Açu, in the municipality of São João da Barra, Rio de Janeiro State, Brazil, their economic relations with the region and their relationship with local public agencies. The paper was based on field research data, as well as bibliographic and documentary research, which had as its goal the survey of data unpublished so far. Its results show that, given the complexity of the operations developed by them, the commercial relations with local companies are fragile. Particularly, spending on the purchase of equipment and skilled workforce has not been and will not be carried out locally any time soon, which limits the ability to drive these investments into the local/regional economy.

Keywords: Açu Port. Employment. São João da Barra.

\footnotetext{
Hevilmar Carneiro Rangel

Doutor em Planejamento Regional e Gestão da Cidade - Universidade Candido Mendes (UCAM-Campos). Mestre em Planejamento Regional e Gestão da Cidade pela UCAM-Campos. E-mail: hcrangel@gmail.com
}

\section{Rosélia Piquet}

Doutora em Teoria Econômica pela Universidade Federal do Rio de Janeiro (UFRJ). Pesquisadora 1 A do CNPq. Professora e coordenadora dos Programas de Mestrado e Doutorado em Planejamento Regional e Gestão da Cidade da Universidade Candido Mendes (UCAM-Campos). E-mail: ropiquet@terra.com.br

\section{Richard de Castro}

Mestre em Planejamento Regional e Gestão da Cidade pela Universidade Candido Mendes (UCAM-Campos). Pós-Graduação Lato Sensu - MBA em Gestão Empresarial pela Fundação Getúlio Vargas (FGV). E-mail: richard.f.castro@hotmail.com 


\section{Introdução}

O texto tem como objetivo analisar o papel do Complexo Portuário e Industrial do Açu em seus aspectos econômicos no município de São João da Barra (RJ), sede do Complexo. Tendo em vista que empreendimentos de grande porte como os do Porto do Açu provocam impactos profundos nos locais de sua implantação, causando uma verdadeira ruptura com o contexto econômico, social e ambiental anteriores à sua chegada, 0 texto procura analisar as relações estabelecidas entre o empreendimento, o município e a região em que se localiza.

A forte demanda internacional de commodities agrícolas e minerais, aliada ao desaparelhamento dos portos públicos brasileiros, levou a modificações na legislação portuária, permitindo que a iniciativa privada construísse e operasse terminais privados no País.

Em dezembro de 2006, o Complexo veio a ser o primeiro terminal privado do País, implantado pelo Grupo EBX, de propriedade do empresário Eike Batista.

Nos anos entre o início das obras até 2013, ocorreram profundas modificações no Grupo EBX, que entra em rápido declínio, e, em dezembro desse mesmo ano, o grupo norte-americano EIG Global Holding tornou-se o principal acionista, assumindo o controle do empreendimento. Embora com atrasos, as obras portuárias foram retomadas.

O Complexo Portuário do Açu tornou-se, então, de propriedade da empresa Prumo Logística Global, controlada pelo EIG Global Energy Partners, fundo americano que opera nos setores de energia e infraestrutura e que passa a deter $91,7 \%$ do capital da empresa.

0 texto tem como objetivo apresentar e analisar o estágio atual em que se encontra a implantação das empresas que se localizam na retroárea portuária e as relações comerciais estabelecidas com a região, em especial, com o município. A elaboração do texto baseou-se em dados de pesquisa de campo, além de levantamento bibliográfico e documental, que teve como objetivo identificar o perfil das novas empresas e seu relacionamento com as administrações locais. A pesquisa de campo foi desenvolvida por meio de entrevistas semiestruturadas com altos administradores das empresas e com lideranças municipais, o que permitiu o conhecimento de dados inéditos sobre o Complexo Portuário.

\section{0 porto e as empresas nele localizadas}

Como o Porto do Açu está estrategicamente localizado ao norte do estado do Rio de Janeiro, próximo às Bacias de Campos, de Santos e do Espirito Santo, seu posicionamento lhe confere condições de acesso marítimo e apoio logístico às empresas petrolíferas que atuam nas principais áreas de exploração e produção de petróleo e gás offshore, o que pode ser visualizado no mapa apresentado na Figura 1.

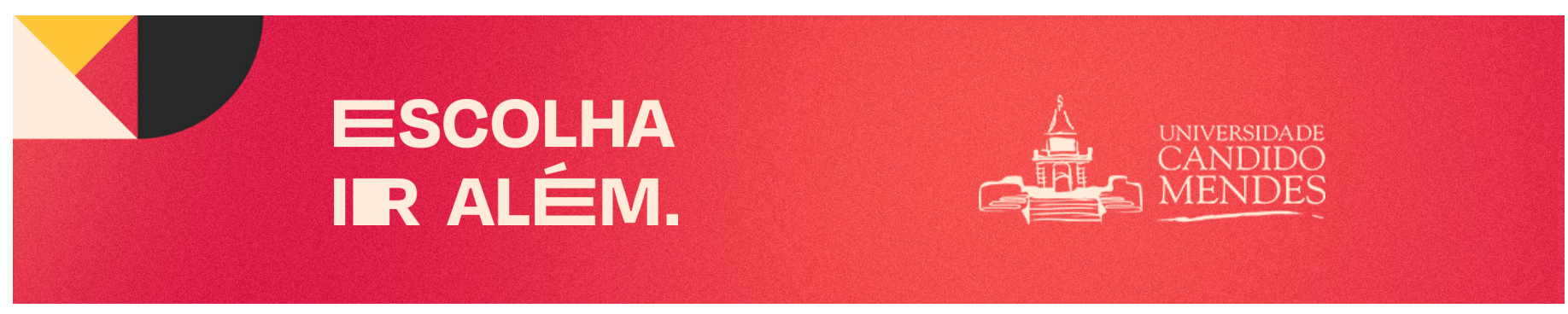




\section{Figura 1: Mapa de acesso ao Porto do Açu}



Fonte: Porto do Açu, 2019

Devido à sobrecarga que já vinha ocorrendo na base de apoio offshore, localizada em Macaé, e à estratégia da Prumo no sentido de fortalecer o papel do Porto do Açu como alternativa logística ao segmento de petróleo e gás, a localização de novas empresas em sua retroárea tornou-se intensa. É nessa área do Porto que já se encontram localizadas 16 empresas entre prestadoras de serviços e fornecedoras de produtos e equipamentos, entre as quais as 12 empresas pesquisadas.

No presente, o Porto dispõe de nove terminais, destacando-se o Terminal 1, dedicado à movimentação de minério de ferro e ao transbordo de petróleo. No Terminal 2, são operadas as cargas gerais de outros minerais, como carvão e bauxita, e as chamadas "cargas de projetos", tais como tubulações destinadas aos serviços de prospecção e exploração em alto mar, assim como as operações de abastecimento de 64 plataformas, sendo 60 em operação na Bacia de Campos e quatro na Bacia do Espírito Santo.

Efetuou-se o levantamento das empresas que se encontram instaladas no Porto, tendo sido identificado que, atualmente, 16 empresas encontram-se efetivamente instaladas no Complexo. Entre estas, 12 foram analisadas por meio de pesquisa qualitativa com roteiro semiestruturado.

0 roteiro das entrevistas foi organizado em três blocos: inicialmente, constam perguntas gerais com o objetivo traçar o perfil das empresas pesquisadas; o segundo visa identificar as relações comerciais estabelecidas entre a empresa entrevistada e as demais empresas do Porto e da região; o terceiro objetiva identificar como as empresas se relacionam com as autoridades locais.

Dado que houve o compromisso da não divulgação da identidade tanto das empresas quanto dos entrevistados, será apresentada a Tabela 1 contendo apenas o perfil desse conjunto segundo o país de origem; o início da operação no Porto; a atividade principal que desenvolve no Brasil; e o número de empregados. 
Tabela 1 - Relação de empresas pesquisadas no Porto do Açu

\begin{tabular}{c|c|c|c|c|l}
\hline $\begin{array}{c}\text { Empres } \\
\mathbf{a}\end{array}$ & $\begin{array}{c}\text { Joint } \\
\text { ventur } \\
\mathbf{e}\end{array}$ & $\begin{array}{c}\text { País de } \\
\text { origem }\end{array}$ & $\begin{array}{c}\text { Início de } \\
\text { operaçã } \\
\text { o }\end{array}$ & $\begin{array}{c}\mathbf{N}^{0} \text { de } \\
\text { empregado } \\
\mathbf{s}\end{array}$ & \multicolumn{1}{|c}{ Atividade principal } \\
\hline 1 & Sim & França/EUA & 2014 & 400 & $\begin{array}{l}\text { Produção de tubos } \\
\text { flexíveis }\end{array}$ \\
\hline 2 & Não & Brasil & 2017 & 46 & $\begin{array}{l}\text { Logística de abastecimento } \\
\text { das plataformas de } \\
\text { petróleo }\end{array}$ \\
\hline 3 & Não & Inglaterra & 2014 & 140 & $\begin{array}{l}\text { Recebimento, tratamento e } \\
\text { exportação de minério de } \\
\text { ferro }\end{array}$ \\
\hline 4 & Não & Brasil & 2018 & 3.200 & Construção civil \\
\hline 5 & Sim & $\begin{array}{c}\text { EUA/Aleman } \\
\text { ha }\end{array}$ & 2018 & 12 & $\begin{array}{l}\text { Geração de energia } \\
\text { elétrica }\end{array}$ \\
\hline 6 & Não & EUA & 2013 & 25 & Administração portuária \\
\hline 7 & Não & EUA & 2013 & 500 & $\begin{array}{l}\text { Produção de tubos } \\
\text { flexíveis }\end{array}$ \\
\hline 8 & Não & Brasil & 2016 & 200 & Construção civil \\
\hline 9 & Sim & EUA/lnglaterr & 2015 & 40 & Transbordo de petróleo \\
\hline 10 & Não & Brasil & 2015 & 20 & $\begin{array}{l}\text { Aluguel de armazéns e } \\
\text { terminal marítimo }\end{array}$ \\
\hline 11 & Sim & EUA/Holanda & 2017 & 50 & $\begin{array}{l}\text { Serviços diversos para } \\
\text { embarcações navais }\end{array}$ \\
\hline 12 & Não & EUA & 2016 & 250 & $\begin{array}{l}\text { Operação e logística } \\
\text { offshore }\end{array}$ \\
\hline
\end{tabular}

Fonte: Dados da pesquisa de campo realizada em julho de 2019

Pelos dados da Tabela, veem-se que predominam grandes empresas que atuam em âmbito multinacional, muitas delas líderes mundiais em produtos ou serviços dos setores nos quais atuam. No conjunto das empresas pesquisadas, predominam as que prestam serviços especializados voltados à produção e ao abastecimento de plataformas e ao transbordo de petróleo.

Sete dessas empresas são de nacionalidade norte-americana, sendo três exclusivamente americanas e quatro em joint venture com empresas de países europeus (França, Alemanha, Inglaterra e Holanda). Entre estas, duas são grandes produtoras de tubos flexíveis aplicados na produção offshore de águas profundas e ultraprofundas dos campos petrolíferos.

Entre as quatro empresas brasileiras, uma delas é a encarregada da construção das duas termelétricas previstas para o Porto, e a outra é responsável pela construção do centro de convivência (hotel, lojas e restaurantes). São, portanto, de atuação temporária. Quanto às demais, uma é grande empresa nacional do setor petrolifero, e outra trabalha com aluguel de armazéns e terminal marítimo.

Cabe destacar o papel da empresa Anglo American, multinacional inglesa de porte internacional, responsável, na área do Porto, pelo recebimento e tratamento de secagem do minério de ferro procedente de Minas Gerais para os navios de transporte internacional. Embora não empregando grande contingente de funcionários, desempenhou papel histórico, visto que, inicialmente, o objetivo da implantação do Porto foi o de ser um grande terminal marítimo de exportação de minério de ferro.

Uma vez que o Porto entrou em fase operacional a partir de 2014, a implantação das empresas ocorreu a partir dessa data, à exceção de uma, portanto, a partir do período de gestão da Prumo Logística. No total, as empresas instaladas já investiram valores superiores a R\$ 10 bilhões, segundo dados da Prumo de 2018 (apud Rangel, 2018, p. 74).

Passando ao segundo bloco de perguntas - que visam identificar as relações comerciais com empresas da região -, quando os entrevistados foram instados a informar se adquiriam produtos ou serviços localmente, cinco afirmaram que sim, enquanto sete não adquiriam nada. Essa pequena diferença poderia, à primeira vista, parecer animadora em relação aos efeitos positivos que as empresas estariam exercendo sobre as empresas regionais. Contudo, quando se perguntava que tipo de produto ou serviço era demandado, as respostas, invariavelmente, eram: pequenas compras de material de escritório e produtos alimentícios em pequenas quantidades; quanto à contratação de serviços, apenas os 
de limpeza e a manutenção de equipamentos de escritório, tais como ar-condicionado, reparos elétricos e hidráulicos. Todos afirmaram que as atividades propriamente industriais, assim como as de transporte e transbordo de óleo, devido à sua complexidade, eram atendidas por outras empresas localizadas no próprio Porto ou por empresas de fora da região.

Os que responderam não comprar "nada" na região procuravam justificar argumentando que, dado o seu porte ou a complexidade das operações que desenvolviam, nenhuma empresa regional apresentava condições de atender à demanda por elas exercida. Cabe destacar que os entrevistados não demonstraram estabelecer diferenciação entre os recursos (empresariais ou de mão de obra qualificada) disponíveis em São João da Barra ou em Campos dos Goytacazes, cidade que atualmente possui cerca de 500 mil habitantes e é polo regional no Norte Fluminense. A maior parte declarou adquirir os produtos no Rio de Janeiro ou diretamente de fábricas localizadas em outros estados. Apenas uma das multinacionais explicou que todos os insumos industriais eram provenientes da Dinamarca, pois nem sequer o Brasil dispunha deles. As relações com as demais empresas do Porto praticamente ocorrem apenas com a Prumo Logística por ser a administradora do Porto.

As respostas surpreendem quando são específicas quanto às relações da empresa com o setor público dos municípios: dez entre as 12 empresas entrevistadas afirmaram não manter relacionamento com o setor público, a não ser os estritamente formais, exercidos por funcionários encarregados do pagamento de taxas e impostos, licenças e outras tarefas burocráticas. Apenas duas empresas afirmaram ter bom relacionamento com secretários da Prefeitura de São João da Barra.

0 número de postos de trabalho das empresas entrevistadas atinge 4.880 postos. Destes, 1.680 , em atividades permanentes e 3.200, em atividades temporárias, na construção das termelétricas e no centro de convivência. Observando-se os dados da Tabela - síntese anterior -, verifica-se que existe grande diferenciação entre elas quanto aos empregos gerados, indo de 3.200 empregados até o extremo oposto, de apenas 12, dado que as áreas de atuação são diferenciadas.

Um ponto valorizado no levantamento de campo foi o de avaliar não só o quanto as empresas ofereciam em termos de postos de trabalho, mas principalmente se existiria algum esforço de aproveitamento da mão de obra local como também se realizavam treinamento de pessoal.

No que respeita ao treinamento, a quase totalidade dos entrevistados afirmou que as contratações, de modo geral, são feitas com pessoal já qualificado para as funções que irá assumir, sendo orientado durante uma ou duas semanas quanto à estrutura organizacional da empresa e aos processos específicos de trabalho. Foram citados os seguintes tipos de treinamento específico: trabalho em ambiente confinado, segurança em altura; trabalho com máquinas rotativas, pontes rolantes, operações de ancoragem; segurança nas tarefas em plataformas, procedimentos nas operações de transbordo. As normas desse item foram indicadas como as mais rigorosas, dada a elevada probabilidade de vazamentos perigosos quanto ao meio ambiente. Todos os entrevistados afirmaram serem as normas de segurança e a prevenção de acidentes rigorosamente exigidos de seus funcionários por todas as empresas localizadas no Porto.

Com a entrada de empresas tão distintas das até então existentes no município, torna-se evidente a ruptura que ocorreria na composição do emprego local, o que será analisado no item 2. 


\section{Uma avaliação do cenário econômico no município}

A economia do município cresceu e se tornou importante desde a colonização da Região Norte Fluminense graças à construção de um porto fluvial, próximo à foz do rio Paraíba do Sul, que permitia a saída da produção da região, como açúcar, aguardente, café, couros, carnes e aves para distribuição no mercado nacional. Este porto atingiu seu auge no final do século XVIII até meados do século XIX, trazendo prosperidade para o município.

Com a chegada da ferrovia, o porto entrou em decadência, assim como a economia do município que, durante muitos anos, passou a depender de uma fraca atividade rural e da produção de três empresas: a Companhia Açucareira Usina Barcelos, que fabricava açúcar e álcool; o Grupo Thoquino, fabricante do conhecido Conhaque de Alcatrão São João da Barra; e a Tecex Fiação e Tecelagem, fabricante de fios e tecidos. (UENF, 2016, p.15, apud Castro, 2019). Dessas empresas, apenas o Grupo Thoquino permanece em atividade; a primeira delas foi desativada em 2009, e a segunda, em 2008.
A economia do município só não entrou em colapso total graças às receitas oriundas dos royalties do petróleo, que crescem a partir de 2008, causando forte aumento na receita municipal até 2014, conforme apresentado na Tabela 2. Entretanto, uma forte crise afetou a indústria do petróleo a partir de 2015, atingindo seu auge em 2016. Este fato provocou uma queda na arrecadação de royalties, que afetou fortemente os municípios dependentes dessa receita. Entre 2012 e 2016, a diminuição das receitas de royalties em São João da Barra foi de 71\%; em Macaé, de 63\%; e, em Campos dos Goytacazes, de $81 \%$.

Tabela 2 - Arrecadação de royalties nos municípios de São João da Barra, Macaé e Campos dos Goytacazes (MR\$)

\begin{tabular}{r|r|r|r}
\hline ano & $\begin{array}{c}\text { São João da } \\
\text { Barra }\end{array}$ & Macaé & \multicolumn{1}{c}{$\begin{array}{c}\text { Campos dos } \\
\text { Goytacazes }\end{array}$} \\
\hline 2006 & 112.023 & 833.452 & 1.735 .697 \\
\hline 2007 & 89.925 & 692.406 & 1.520 .183 \\
\hline 2008 & 293.786 & 920.878 & 2.134 .980 \\
\hline 2009 & 292.837 & 675.374 & 1.724 .859 \\
\hline 2010 & 335.699 & 683.889 & 1.682 .407 \\
\hline 2011 & 390.192 & 752.778 & 1.916 .640 \\
\hline 2012 & 343.419 & 798.631 & 1.993 .676 \\
\hline 2013 & 316.393 & 719.863 & 1.806 .139 \\
\hline 2014 & 309.228 & 713.526 & 1.579 .796 \\
\hline 2015 & 190.246 & 413.003 & 741.370 \\
\hline 2016 & 98.600 & 291.985 & 387.087 \\
\hline 2017 & 122.953 & 429.840 & 502.761 \\
\hline 2018 & 168.885 & 624.863 & 698.804 \\
\hline
\end{tabular}


No entanto, como o Porto do Açu já se encontrava em operação em 2016, a queda na arrecadação de royalties afetou São João da Barra com um impacto menor do que nos demais municípios, pois houve um crescimento de outros tipos de receita provenientes, principalmente, de atividades industriais, de construção civil e de serviços.

Os dados da Tabela 3, contudo, indicam o forte papel que o início da construção do Porto, em 2006/2007, teve no crescimento de impostos em São João da Barra. Fica evidente que esse aumento pode ser atribuído ao complexo portuário, pois o crescimento deste imposto supera, de forma surpreendente, outros do Norte Fluminense. Do mesmo modo, destaca-se a arrecadação de Imposto sobre Serviço de Qualquer Natureza (ISS), afeto principalmente a atividades na construção civil, que em São João da Barra cresce mesmo após a crise de 2016 enquanto, em Macaé e Campos dos Goytacazes, continua a declinar nos anos seguintes.

Tabela 3 - Arrecadação de Imposto Sobre Serviço de Qualquer Natureza (ISS) (MR\$)

\begin{tabular}{|c|c|c|c|c|c|c|c|c|}
\hline & 2006 & 2008 & 2010 & 2012 & 2014 & 2016 & 2018 & $\begin{array}{c}\text { Evolução } \\
2018 / 200 \\
6 \%\end{array}$ \\
\hline São João da Barra & 920 & $\begin{array}{r}7.264 \\
207.54\end{array}$ & $\begin{array}{r}9.005 \\
301.86\end{array}$ & $\begin{array}{l}33.029 \\
473.74\end{array}$ & 63.743 & $\begin{array}{l}43.094 \\
597.25\end{array}$ & $\begin{array}{l}50.401 \\
494.61\end{array}$ & 5.378 \\
\hline Macaé & 110.954 & 5 & 1 & 6 & $\begin{array}{r}611.696 \\
105.83\end{array}$ & 0 & 3 & 346 \\
\hline Campos dos Goytacazes & 26.117 & 42.445 & 70.684 & 94.270 & 6 & 89.335 & 81.208 & 211 \\
\hline
\end{tabular}

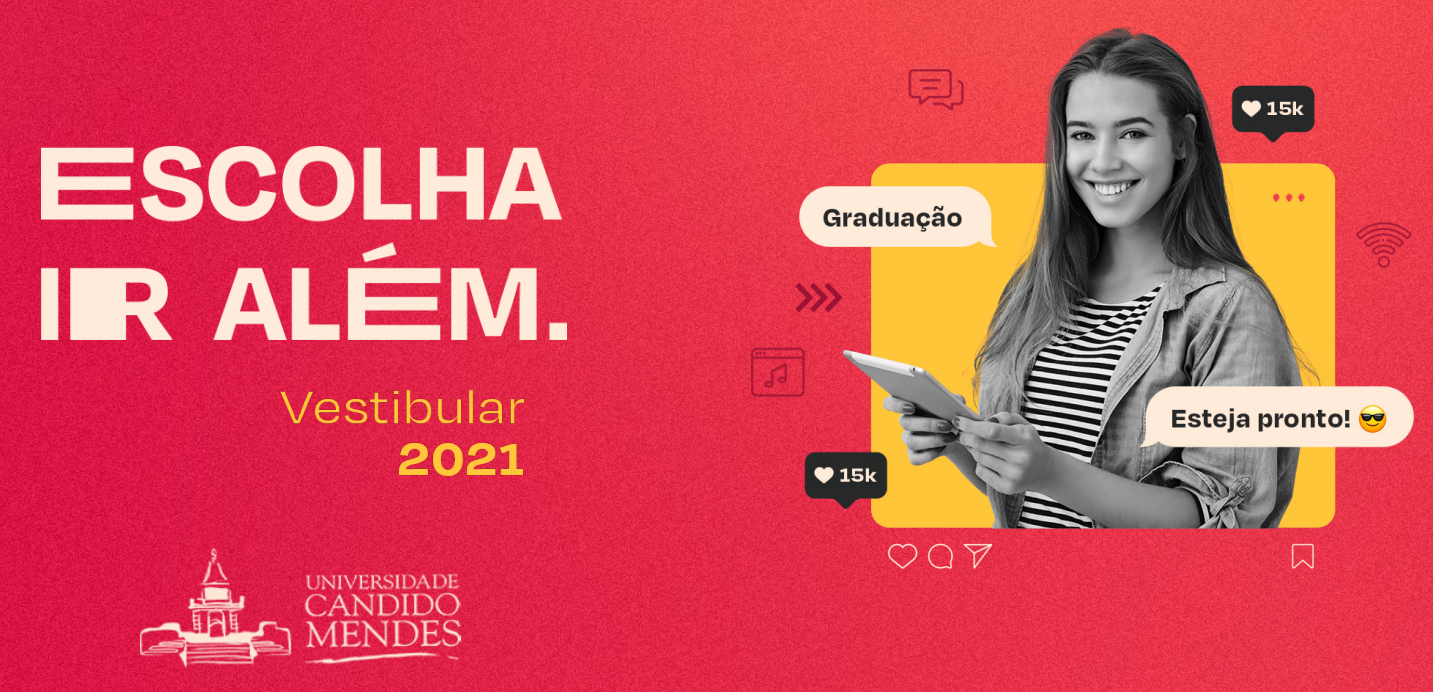


O Imposto sobre Circulação de Mercadorias e Serviços (ICMS) é um imposto estadual sobre operações relativas à circulação de mercadorias e sobre prestações de serviços de transporte interestadual e intermunicipal e de comunicação, do qual, 25\% são destinados ao município que participa desta arrecadação.

Trata-se de uma importante fonte de arrecadação dos três municípios pesquisados, no entanto, em São João da Barra, isso se dá de forma muito mais significativa que nos demais. Em especial, observa-se, no período de 2016 e 2018, um aumento de 141\% desse imposto em São João da Barra. No mesmo período, esse crescimento foi de 25\%, em Macaé, e de 23\%, em Campos dos Goytacazes. A arrecadação de ICMS, demonstrada na Tabela 4, em 2016, caiu em Macaé e Campos dos Goytacazes, não afetando São João da Barra.

Tabela 4 - Arrecadação de Imposto sobre Circulação de Mercadorias e Serviços (ICMS) (MR\$)

\begin{tabular}{|c|c|c|c|c|c|c|c|c|}
\hline & 2006 & 2008 & 2010 & 2012 & 2014 & 2016 & 2018 & $\begin{array}{c}\text { Evoluçã - } \\
2018 / 200 \\
6 \%\end{array}$ \\
\hline São João da Barra & 12.317 & $\begin{array}{l}15.849 \\
152.68\end{array}$ & $\begin{array}{l}21.222 \\
229.84\end{array}$ & $\begin{array}{l}26.619 \\
282.52\end{array}$ & $\begin{array}{c}31.248 \\
331.25\end{array}$ & $\begin{array}{c}36.395 \\
325.42\end{array}$ & $\begin{array}{l}87.607 \\
407.54\end{array}$ & 611 \\
\hline Macaé & $\begin{array}{l}98.552 \\
103.60\end{array}$ & $\begin{array}{r}9 \\
138.76\end{array}$ & $\begin{array}{r}6 \\
188.85\end{array}$ & $\begin{array}{r}7 \\
234.58\end{array}$ & $\begin{array}{c}3 \\
262.22\end{array}$ & $\begin{array}{r}9 \\
214.59\end{array}$ & $\begin{array}{r}3 \\
264.16\end{array}$ & 314 \\
\hline Campos dos Goytacazes & 1 & 4 & 0 & 0 & 1 & 5 & 1 & 155 \\
\hline
\end{tabular}

\section{DOUTORADO \\ COM LINHA DE PESQUISA EM INSTRUMENTOS DE POLÍTICAS PÚBLICAS}

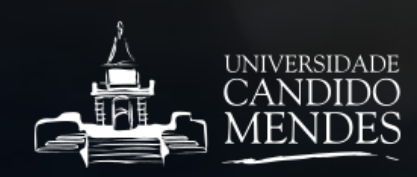




\section{Mudanças do mercado de trabalho}

Para a análise do comportamento do emprego formal em São João da Barra, foram utilizados dados da Relação Anual de Informações Sociais (RAIS) e do Cadastro Geral de Empregados e Desempregados (CAGED) entre 2006, ano que antecede o início da implantação do Porto, e 2018.

Os dados contidos na Tabela 5 indicam movimentos distintos: em primeiro lugar, a crise econômica que afeta o País torna-se dramaticamente evidenciada quando se observa que, entre 2014 e 2018, foram fechados três milhões e duzentos mil postos de trabalho no Brasil, equivalendo a uma queda de $6 \%$ no estoque de empregos, como resultado da crise econômica que se instalou no País. No estado do Rio de Janeiro, essa perda foi de $12,6 \%$ e, na Região Norte Fluminense, de $18,2 \%$.

Tabela 5 - Estoque de empregados formais em municípios selecionados - NF, ERJ e Brasil

\begin{tabular}{|c|c|c|c|c|c|c|c|c|c|}
\hline & 2006 & 2008 & 2010 & 2012 & 2014 & 2016 & $2018^{*}$ & $\begin{array}{c}\text { Variação } \\
2018 / 200 \\
6\end{array}$ & $\begin{array}{c}\text { Evolução } \\
\text { 2018/2006 } \\
\%\end{array}$ \\
\hline \multirow[t]{2}{*}{ São João da Barra } & 3.994 & 5.312 & 7.397 & 8.873 & 10.415 & 8.362 & 10.679 & 6.685 & 167 \\
\hline & 85.29 & 103.15 & & & & & & & \\
\hline \multirow[t]{2}{*}{ Macaé } & 7 & 9 & 115.775 & 141.734 & 147.840 & 126.871 & 113.970 & 28.673 & 34 \\
\hline & 84.22 & & & & & & & & \\
\hline Campos dos Goytacazes & 4 & 88.230 & 87.380 & 93.541 & 103.218 & 90.282 & 85.405 & 1.181 & 1,4 \\
\hline Norte Fluminense $(x 1.000)$ & 188 & 211 & 227 & 260 & 281 & 243 & 230 & 42 & 22 \\
\hline Est. do RJ (x1.000) & 3.374 & 3.712 & 4.080 & 4.462 & 4.641 & 4.159 & 4.054 & 680 & 20 \\
\hline & 35.15 & & & & & & & & \\
\hline Brasil (x1.000) & 5 & 39.442 & 44.068 & 47.459 & 49.572 & 46.060 & 46.403 & 11.248 & 32 \\
\hline
\end{tabular}

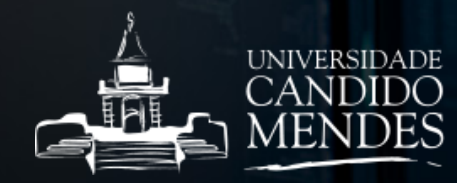


No cenário econômico de São João da Barra entre 2014 e 2016, a redução do emprego formal foi de 19,7\%; porém esta redução ocorreu em virtude da forte desaceleração das obras de empresas que estavam em fase de implantação no Porto, o que resultou na diminuição de $57,8 \%$ do número de trabalhadores na construção civil no município.

Mesmo em um cenário de redução de postos de trabalho formais como o apresentado, São João da Barra mostra uma evolução diferenciada dos demais municípios da região quando se observa o ocorrido entre 2016 e 2018. Enquanto o município recupera a oferta de postos de trabalho, esta permanece em queda em Macaé e em Campos dos Goytacazes, assim como no estado do Rio de Janeiro. No caso de Macaé, a acentuada perda de postos de trabalho pode ser explicada pelo fato de que, além de ter sofrido dos mesmos problemas que afetaram a economia brasileira e o setor petrolífero, as operações de abastecimento das plataformas de petróleo da Petrobras na Bacia de Campos foram transferidas do Porto de Imbetiba, em Macaé, para o Porto do Açu. Pode-se concluir, portanto, que a recuperação de São João da Barra de $167 \%$ na oferta de emprego, marcadamente superior aos demais municípios selecionados, ao estado e ao Brasil, indica a existência de uma força local impulsionando essa tendência, diferentemente daquela que acontece no mercado de trabalho nacional e estadual.
Campos dos Goytacazes, mesmo sendo limítrofe a São João da Barra e município polo da região, apresenta um crescimento de apenas 1,4\% entre 2006 e 2018, o que sugere que, até o momento, a influência proveniente da instalação do Complexo Portuário do Açu ainda é pouco aparente, o que fica confirmado quando se recorda que, na pesquisa de campo, foram indicadas pelos representantes das empresas as frágeis relações comerciais das empresas do Porto com esse município.

A Tabela 6 é reveladora das mudanças na estrutura do emprego em São João da Barra: enquanto, em 2006, a Administração Pública e o Comércio Varejista representavam 62\% do emprego formal, em 2018, essa participação reduziu-se a 36\%. Contrariamente, atividades de baixa representatividade em 2006, tais como a de Indústria Química, de Extrativa Mineral, de Transporte e Comunicações e de Administração Técnica Profissional, que perfaziam apenas 1,8\% dos empregos no município, passaram, em 2018, a representar 35\% do total da oferta, enquanto a Administração Pública reduziu sua participação a 29\%.

\section{Tabela 6 - Estoque de empregados formais por subsetor econômico em São João da Barra}

\begin{tabular}{|c|c|c|c|c|c|c|c|c|c|c|}
\hline & 2006 & 2008 & 2010 & 2012 & 2014 & 2016 & $\underset{*}{2018}$ & $\begin{array}{l}\text { Particip. } \\
\text { em SJB } \\
2006(\%)\end{array}$ & $\begin{array}{l}\text { Paritcip. } \\
\text { em SJB } \\
2018(\%)\end{array}$ & $\begin{array}{c}\text { Evolução } \\
2018 / 200 \\
6 \%\end{array}$ \\
\hline Indústria química & 5 & 4 & 4 & 88 & 848 & 805 & 1.077 & 0,1 & 10,1 & $21.44 C$ \\
\hline $\begin{array}{l}\text { Extrativa mineral } \\
\text { Transporte e }\end{array}$ & 2 & 1 & 0 & 1 & 8 & 170 & 264 & 0,1 & 2,5 & 13.100 \\
\hline & 18 & 61 & 114 & 162 & 201 & 941 & 1.145 & 0,5 & 10,7 & 6.261 \\
\hline profission. & 44 & 63 & 143 & 312 & 256 & 376 & 1.264 & 1,1 & 11,8 & 2.773 \\
\hline Aloj. Comunicação & 190 & 277 & 358 & 538 & 580 & 470 & 403 & 4,8 & 3,8 & 112 \\
\hline $\begin{array}{l}\text { Comércio varej. } \\
\text { Administração }\end{array}$ & 444 & 517 & 600 & $\begin{array}{r}664 \\
2.63\end{array}$ & $\begin{array}{r}787 \\
3.97\end{array}$ & $\begin{array}{r}727 \\
2.78\end{array}$ & 733 & 11,1 & 6,9 & 65 \\
\hline pública & 1.997 & 2.211 & 3.583 & $\begin{array}{r}6 \\
3.13\end{array}$ & $\begin{array}{r}0 \\
2.67\end{array}$ & $\begin{array}{r}2 \\
1.12\end{array}$ & 3.080 & 50,0 & 28,8 & 54 \\
\hline Construção civil & 281 & 1.292 & 1.747 & 3 & 6 & 9 & 1.619 & 7,0 & 15,2 & 476 \\
\hline Subtotal & 2.981 & 4.426 & 6.549 & $\begin{array}{r}7.53 \\
4\end{array}$ & $\begin{array}{r}9.32 \\
6\end{array}$ & $\begin{array}{r}7.40 \\
0\end{array}$ & 9.585 & 74,6 & 89,8 & 222 \\
\hline
\end{tabular}

Fonte: Dados do Ministério do Trabalho (RAIS/CAGED). Elaboração dos autores em 14/08/2019 *Dados do CAGED 
Talvez o maior destaque a ser feito sobre o comportamento do emprego em São João da Barra seja quanto à sua participação na formação do estoque total de empregos: enquanto, em 2006, participou com 2,1\% dos empregos totais da região, em 2018, dobrou essa participação, atingindo $4 \%$, superando todos os demais municípios da Região Norte Fluminense com exceção de Macaé e Campos, que detiveram, respectivamente, $50 \%$ e $38 \%$ dos vínculos empregatícios em 2018 (Castro, 2019, p.37).
29,3\%. A maior participação dos níveis mais elevados de qualificação ressalta o novo perfil exigido pelas atividades do Porto. Enquanto, antes da implantação do Porto, não havia nenhum profissional com curso de mestrado ou doutorado no município, a partir de 2010, surgem os primeiros registros, atingindo o maior contingente em 2014.

Na Tabela 7, constam os dados das mudanças ocorridas nos empregos formais por grau de escolaridade em São João da Barra: enquanto, em 2006, os três primeiros níveis de mais baixa qualificação perfaziam um total de $59 \%$ de sua população, em 2018, essa participação reduziu para

Tabela 7 - Estoque de empregados formais por grau de escolaridade em São João da Barra

$\begin{array}{lllllllllll}2006 & 2008 & 2010 & 2012 & 2014 & 2016 & 2018^{*} & \begin{array}{c}\text { Partcip. } \\ \text { em SJB } \\ 2006(\%)\end{array} & \begin{array}{c}\text { Partcip. } \\ \text { em SJB }\end{array} & \begin{array}{c}\text { Evolução } \\ 2018(\%)\end{array} \\ 6 \%\end{array}$

\begin{tabular}{|c|c|c|c|c|c|c|c|c|c|c|}
\hline Analfabetos & 72 & 41 & 32 & 16 & 11 & 10 & 30 & 1,8 & 0,3 & -58 \\
\hline Fundam. & 1.39 & 1.65 & 2.04 & 1.68 & & 1.17 & & & & \\
\hline incompleto & 1 & $\begin{array}{r}9 \\
1.40\end{array}$ & $\begin{array}{r}7 \\
2.00\end{array}$ & $\begin{array}{r}2 \\
1.58\end{array}$ & 1.629 & $\begin{array}{r}2 \\
1.45\end{array}$ & 1.407 & 34,8 & 13,8 & 1,2 \\
\hline Fundam. completo & $\begin{array}{r}893 \\
1.29\end{array}$ & $\begin{array}{r}2 \\
1.75\end{array}$ & $\begin{array}{r}8 \\
2.48\end{array}$ & $\begin{array}{r}7 \\
4.23\end{array}$ & 1.891 & $\begin{array}{r}7 \\
3.70\end{array}$ & 1.559 & 22,4 & 15,2 & 75 \\
\hline Médio completo & 4 & 9 & 6 & $\begin{array}{r}2 \\
1.33\end{array}$ & 4.505 & $\begin{array}{r}4 \\
1.92\end{array}$ & 4.929 & 32,4 & 48,2 & 281 \\
\hline Superior completo & 344 & 451 & 822 & 4 & 2.273 & 9 & 2.302 & 8,6 & 22,5 & 569 \\
\hline Mestrado/doutorado & 0 & 0 & 2 & 22 & 106 & 90 & $\star *$ & - & - & - \\
\hline & 3.99 & 5.31 & 7.39 & 8.87 & 10.41 & 8.36 & 10.22 & & & \\
\hline Subtotal & 4 & 2 & 7 & 3 & 5 & 2 & 7 & 100 & 100 & 156 \\
\hline
\end{tabular}

Fonte: Dados do Ministério do Trabalho (RAIS/CAGED). Elaboração dos autores em 14/08/2019

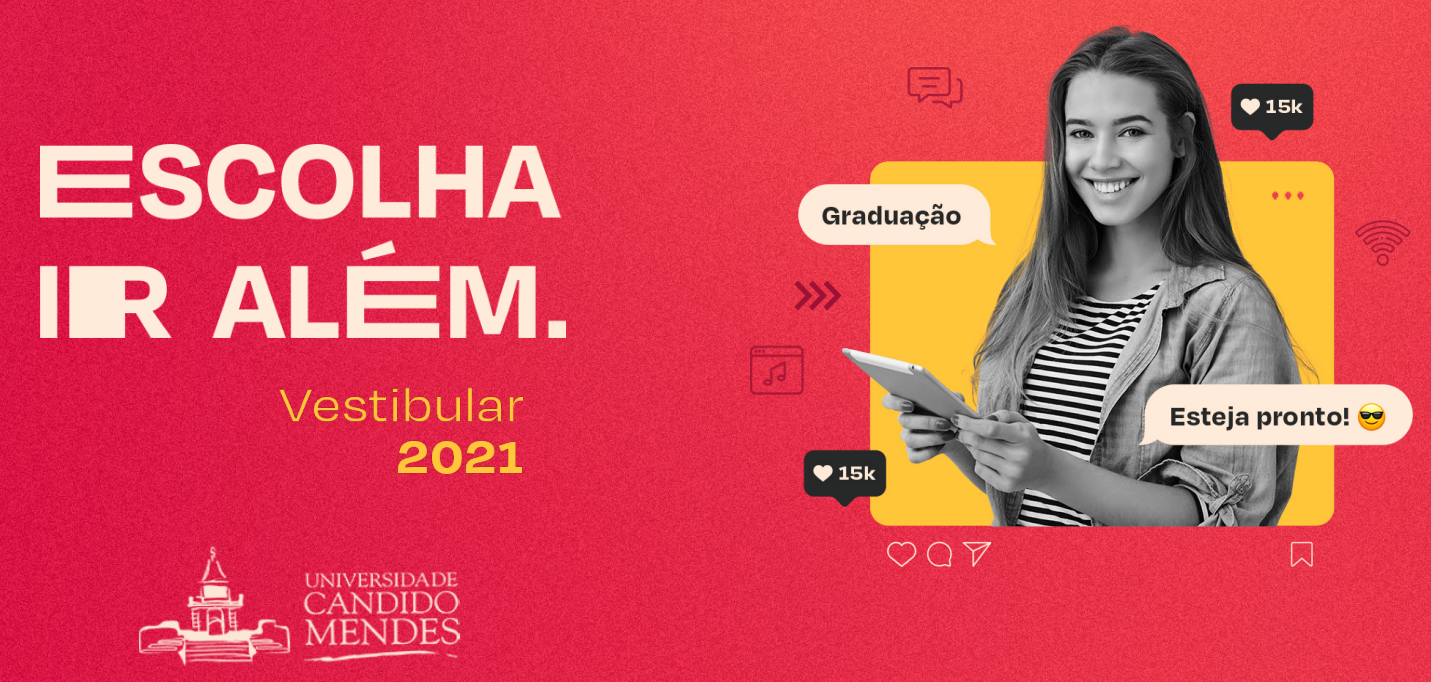


É possível afirmar que essa melhoria na escolaridade do trabalhador formal decorre da presença das novas empresas que se instalaram no Complexo Portuário do Açu, uma vez que operam em segmentos como exploração e produção de petróleo e gás, indústria de transformação de alta tecnologia, operação portuária, transporte marítimo de cargas e serviços de engenharia altamente exigentes quanto à qualificação profissional.

\section{Conclusões}

0 início das operações do Porto do Açu em 2014 e sua crescente consolidação como base de apoio do complexo petrolífero da Bacia de Campos indicam que a Região ao Norte do estado do Rio encontra-se marcada por grandes investimentos articulados à economia mundial e à inserção brasileira na divisão internacional do trabalho como exportador de commodities. As evidências empíricas aqui trazidas apontam para o fato de que a Região Norte Fluminense e particularmente o município de São João da Barra, encontram-se submetidos a um conjunto de mudanças que dará lugar a um intenso processo de requalificação desse espaço, seja qual for o seu resultado em termos de desenvolvimento ou não. Também ficou evidente que esse processo não é resultante de políticas públicas concebidas com tal propósito. Ao contrário, resulta de processos decisórios liderados por grandes empresas nacionais e internacionais.

Reza a literatura que trata das relações porto-cidade que o porto-indústria caracteriza-se por ter pouca relação com seu entorno, suas áreas de influência são longínquas; realizam uma ocupação e um uso intensivo de espaço não urbano, ocupando extensas áreas com as atividades desenvolvidas em sua retroárea, sendo este o quadro encontrado no município pesquisado.

As entrevistas indicam que parte substancial dos investimentos na implantação das empresas - especialmente os gastos com aquisições de máquinas, equipamentos, projetos de engenharia e mão de obra especializada não foram, nem serão tão cedo, contratadas no entorno do Porto, no estado e, em alguns casos, nem mesmo no País, o que limita, e muito, a capacidade indutora desses investimentos sobre a economia local/regional.

Com o redirecionamento do projeto do Porto, quando da passagem do controle do Grupo EBX - cujo projeto de sua retroárea era baseado em empresas de setores industriais diversos, com estratégias diferenciadas para a multinacional Prumo Logística, a zona industrial perdeu sua feição multifuncional anteriormente prevista e passou a centrar suas atividades no processamento e na exportação do minério de ferro e, sobretudo, no apoio logístico às plataformas offshore das Bacias de Campos e do Espírito Santo. Como afirma Monié (2016), "em consequência disso, a zona industrial portuária participará de um espaço de fluxos de menor complexidade: exportação de commodities e logística de curto alcance destinada às unidades de extração de óleo".

É ponto de acordo na literatura que trata dos impactos de grandes empreendimentos, que estes - os agentes mais poderosos na reestruturação do espaço - têm sido os das grandes corporações, cujas ações podem acentuar - em lugar de mitigar - as desigualdades regionais. Nesta mesma linha de argumentação, Bercker (2006) chama atenção para o fato de que, apesar do fortalecimento da sociedade civil organizada, as redes atuais, grosso modo, reproduzem o padrão histórico de conexão das áreas produtoras aos portos, criando, assim, extensos territórios logísticos de escoamento, os quais têm sido mais funcionais em relação à lógica dos negócios dessas empresas do que em relação ao desenvolvimento local-regional.

Embora com todas as limitações indicadas pela literatura que versa sobre o tema, é oportuno reconhecer que as atividades do Complexo Portuário do Açu proporcionaram benefícios econômicos ao município sob a forma de aumento da oferta de empregos formais e elevação de impostos, assim como novo destaque no cenário regional. Se esses benefícios de curto prazo serão ou não ampliados e sustentados, resultantes do embate e da colaboração entre agentes públicos, produtivos e sociais da região, só o tempo irá responder. 


\section{Referências}

ANGELIS, ngelo. Guerra Fiscal dos Portos e Desenvolvimento Regional no Brasil. Revista de Desenvolvimento Regional, Santa Cruz do Sul v. 18, n.1, p., $185-212$, jan./.abril 2013.

BRANDÃO, C. A. Mudanças produtivas e econômicas e reconfiguração territorial no Brasil no início do século XXI. Revista Brasileira de Estudos Urbanos e Regionais, São Paulo, v. 21, n. 2, p. 258-279, maio/ago. 2019.

BECKER, Berta (coord.). Logística e Ordenamento Territorial. Relatório preparado como subsídio à elaboração da Política Nacional de Ordenamento Territorial - PNOTT, 2006

BRASIL. Ministério da Economia. Secretaria de Trabalho. Bases Estatísticas RAIS e CAGED. Disponível em: http://bi.mte.gov.br/bgcaged/inicial.php. Acesso em: 14 ago. 2019.

CASTRO, Richard. 0 novo perfil do emprego em São João da Barra: um estudo sobre a influência da implantação de um grande empreendimento, o Complexo Portuário do Açu. 2019. 111 f. Dissertação (Mestrado em Planejamento Regional e Gestão da Cidade) Universidade Candido Mendes, Campos dos Goytacazes, RJ, 2019.

GUSMÃO, Paulo. Apropriação e Ordenamento Territorial na Zona Costeira do Estado do Rio de Janeiro. Estudo Urbanos e Regionais, v.12, n. 2, nov. 2010.

MONIÉ, Frédéric. Análise geopolítica dos conflitos na área de influência do complexo portuário e industrial do Açu - São João de Barra, RJ. Cadernos do Desenvolvimento Fluminense, Rio de Janeiro,n. 9, , p. 169-83, jan./jun. 2016.

MONIÉ, Frédéric . Dinâmicas Produtivas, Logística e Desenvolvimento Territorial. In: Videira, S. L.; Costa, P. A. e Fajardo, S.( orgs.) Geografia Econômica: (re)leituras contemporâneas. Rio de Janeiro: Letra Capital, 2011.

PORTO DO AÇU. Mapa de acesso ao Porto do Açu. Disponível em:https://portodoacu.com.br/fotos/. Acesso em: 25 abr. 2011. 